\title{
PATRINIÓNIO NIUSICAL NA CATEDRAL DE ANGRA NO SÉCULO XVII: TRÊS LIVROS DE POLIFONIA VOCAL SACRA E O SEU POSSÍVEL CONTEXTO
}

Musical heritage in Angra Cathedral in the seventeenth century: three books of sacred vocal polyphony and their possible context

\section{Luís Henriques}

E-mail: luiscfhenriques@gmail.com

CESEM/Universidade de Évora 


\title{
Resumo
}

A Catedral de Angra foi, desde a sua fundação em 1534, um importante centro musical na ilha Terceira e no arquipélago dos Açores. Embora a sua atividade musical não seja conhecida em detalhe, várias referências documentais sugerem que esta seria pelo menos próxima das catedrais do continente português. Um dos testemunhos documentais é a existência na Catedral de três livros de coro impressos de polifonia vocal sacra de dois dos mais conhecidos compositores portugueses da primeira metade do século XVII: Duarte Lobo e Fr. Manuel Cardoso. O período em que estes livros foram impressos $(1605,1613$ e 1621) foi marcado por agitação na cidade de Angra durante a ocupação espanhola. Simultaneamente, a construção da nova Catedral durou quase um século, perturbando a sua atividade litúrgico-musical regular. Partindo dos três livros de polifonia existentes, o presente estudo analisa o património musical da Catedral durante a primeira metade do século XVII e a sua ralação com o seu contexto circundante.

Palavras-chave: Catedral de Angra; Património musical; Livros de polifonia; Paisagem sonora.

\begin{abstract}
The Cathedral of Angra was, since its foundation in 1534, an important musical centre in the island of Terceira and in the Azores archipelago. Although its musical activity is not known in detail, several documental references suggest that it was at least very close to the mainland Portuguese cathedrals. One of these documental testimonies is the existence in the Cathedral of three printed sacred vocal polyphony choirbooks by two of the most known Portuguese composers of the first half of the seventeenth century: Duarte Lobo and Fr. Manuel Cardoso. The period in which these books were printed $(1605,1613$ and 1621) was marked by unrest in the city of Angra during the Spanish occupation. Simultaneously, the construction of the new Cathedral lasted for almost a century, disrupting its regular liturgical-musical activity. Departing from the three existing polyphonic books, the present study analyses the Cathedral's musical heritage during the first half of the seventeenth century and the relation with its surrounding context.
\end{abstract}

Keywords: Angra Cathedral; Musical heritage; Polyphony books; Soundscape. 
A cidade de Angra foi um importante centro estratégico nas navegações dos portugueses entre os séculos XVI e XVIII, constituindo um ponto de paragem e abastecimento nas rotas atlânticas. Este estatuto, aliado à sua elevação a cidade e sede de diocese em 1534, consolidou a sua centralidade atlântica ao longo de quinhentos e seiscentos (Costa, 2008,132). Em termos históricos, Angra foi ainda entre o final do século XVI e meados de seiscentos, um dos palcos principais das disputas entre Portugal e Castela pela soberania portuguesa, sendo também um período rico em eventos que, direta ou indiretamente, tiveram consequências na sua paisagem sonora. Este período de crise, até à consolidação da Restauração nas ilhas, correspondeu ainda à construção da nova Catedral de Angra, obra que causou certamente um profundo impacto na dinâmica da cidade.

A segunda metade do século XVI e centúria seguinte foi marcada pelas iniciativas litúrgico-musicais emanadas do Concílio de Trento, constituindo a música um importante elemento da Contra-Reforma. No que concerne às reformas emanadas de Trento, estas refletiram-se na aceitação pelas igrejas portuguesas das normas litúrgicas unificadas, no âmbito litúrgico-musical pela imposição do Missal e Breviário romanos, editados durante pontificado de Pio V, constituindo a versão oficial dos textos destinados à celebração da Missa e do Ofício Divino respetivamente. Não tiveram, todavia, um impacto imediato, uma vez que nem o Concílio nem as várias comissões criadas posteriormente conseguiram produzir uma versão unificada do cantochão correspondente aos textos oficiais suficientemente forte para ser imposta ao mundo católico (Nery e Castro, 1992, p. 50). Por exemplo, na Capela Real de Lisboa, o Passionário em vigor nessa instituição da autoria de Jacob Fernandes Fermoso (impresso em 1543) foi substituído por um novo, da autoria do padre Manuel Cardoso (impresso em 1575), "conforme o missa da impressam de Plantino, \& ao breuiario que nouamente foram ordenados \& impressos, por decreto do sagrado Concilio Tridentino" e, em 1595, este foi, por sua vez, substituído por um outro da autoria de Fr. Estêvão de Cristo (Nery e Castro, 1992, p. 50-51). No entanto, a partir do final do século XVI parece existir uma dicotomia entre o repertório musical realizado na Capela Real e nas capelas palacianas e aquele realizado nas catedrais portuguesas. Por um lado, as capelas palacianas possuíam um repertório exclusivo, visando uma elite de ouvintes dotados de uma cultura e conhecimento musical sofisticado, demonstrando desse modo uma maior abertura a ideias estéticas mais diversificadas e complexas, assim tecnicamente mais exigentes. Por outro lado, o repertório das capelas catedralícias destinava-se a atrair um grande público e, por isso mesmo, era quase sempre de uma natureza mais austera e simples, assentando quase sempre num estilo de escrita imitativa a quatro vozes (Nery e Castro, 1992, p. 51). Este parece ser o caso da Catedral de Angra, reportando-se à presença nesta Catedral dos livros objeto de estudo do presente trabalho.

A distinção entre estes dois contextos musicais (palaciano e catedralício) torna-se importante referir, uma vez que uma grande percentagem da polifonia portuguesa impressa e escrita em manuscrito ao longo da primeira metade do século XVII 
corresponde ao corpus de repertório marcadamente mais conservador e, deste modo, destinado a um contexto catedralício transmitindo, por vezes, uma imagem parcial e redutora, da diversidade e riqueza da prática polifónica em Portugal (Nery e Castro, 1992, p. 51-52).

Em termos musicais, a criação da Diocese de Angra em 1534 iniciou uma fase de estabelecimento de certas estruturas e cargos de natureza musical na igreja de São Salvador que, de um momento para o outro, se viu como o principal estabelecimento eclesiástico da cidade. Começou com o aumento do salário do organista que aí servia, ordenado a 18 de outubro de 1540. A 27 de abril de 1553 foi ordenada a criação e adição de quatro moços do coro ao efetivo musical da igreja que nessa altura servia de Catedral e, a 3 de julho de 1561, mais dois moços, provenientes do colégio dos órfão, que servissem no coro, mas também no altar e onde a sua presença fosse requerida. Em 1567 é criado oficialmente o cargo de mestre de capela da Catedral que, para além das funções de direção musical da capela, tinha também a obrigação de ensinar cantochão e canto de órgão a quem quisesse aprender, assim como ensinar vinte moços pobres indicados pelo bispo (Henriques, 2012, p. 64). Resumidamente, esta foi a cronologia do estabelecimento progressivo dos cargos musicais na Catedral de Angra, pelo que, já nas últimas décadas do século XVI estava esta instituição guarnecida das estruturas-base que asseguravam o serviço litúrgico-musical. A partir de meados do século XVI, possuía um mestre de capela, responsável por um grupo de seis capelães-cantores e quatro moços do coro, assim como um organista, tendo também a incumbência de ensinar os dois estilos musicais vigentes à época: o cantochão, compreendendo a grande percentagem do repertório musical que era cantado na celebração dos ofícios diários no coro da Catedral, e o canto de órgão ou polifonia, o repertório que era utilizado como meio de solenizar determinadas festas do calendário litúrgico.

Paralelamente ao desenvolvimento da sua estrutura musical, também se desenvolveu a própria estrutura física do templo que servia de Catedral. Por se achar exígua a primitiva igreja de São Salvador, foi decidido construir um novo templo que servisse de Catedral, digno da diocese que então se havia criado. O lançamento da primeira pedra foi realizado a 18 de novembro de 1570, seguindo o cerimonial próprio. A comunidade saiu em procissão da igreja de São Salvador, que ficava no local onde se iria erigir o novo edifício, em direção ao local onde seria colocada a pedra fundacional. Neste cortejo tomou parte o Cabido da Catedral, a colegiada de Nossa Senhora da Conceição, o desembargador, o provedor da fazenda, armada e fortificações, o juiz, o senado, o procurador da cidade, outras figuras da administração da cidade e muito povo. Presidiu à cerimónia o deão Baltazar Gonçalves, tendo o mesmo colocado a pedra, estando presentes também os cónegos da Catedral (Mota, 2007, p. 28). A obra da Catedral teve como seu primeiro mestre Luís Gonçalves Cotta, a que é também atribuída a autoria da respetiva traça, constituindo um dos primeiros casos nas ilhas açorianas de um templo que contraria a tradicional orientação Nascente-Poente, condicionada por 
imposições urbanísticas (Laranjeira, 2008, p. 14). O longo período que demorou a construção da nova Catedral acompanhou os desenvolvimentos políticos do reino que se refletiram profundamente na dinâmica da ilha Terceira. Ainda em 1572 o rei D. Sebastião enviava a Angra um novo traçado para a nova Catedral. No entanto, as obras pararam no ano de 1583 por via das lutas da Sucessão, que se vinham agravando desde 1580 , sendo os fundos encaminhados para a defesa e fortificação da ilha (Laranjeira, 2008, p. 15). As obras retomaram em 1590 por determinação de D. Filipe II, porém, a um ritmo certamente mais lento que anteriormente uma vez que em 1592 uma parte substancial dos fundos foi desviada para a grande fortaleza que se começou a erguer no Monte Brasil (Laranjeira, 2008, p. 16). Em 1608, Luís Mendes foi nomeado mestre das obras da Catedral. Em 1609 prepararam-se planos para a construção de um claustro anexo à Catedral o que veio a efetivar-se, sendo Baltazar Álvares o autor da respetiva traça (Leite, 2015, p. 44). Este espaço, como nas outras catedrais portuguesas (veja-se, por exemplo o caso da Catedral de Évora), transformava-se em local de ensino e do cultivo das artes e humanidades, sugerindo as iniciativas para a sua construção em Angra de um claustro haver necessidade da sua existência, nomeadamente também para a realização de certas procissões.

De acordo com o padre Manuel Luís Maldonado, obras de pedraria e alvenaria da Catedral terão terminado por volta do ano de 1618, porém afirma que "de seus inspetores não houve boa fama, pelo desperdício que se lhes notou na distribuição dos muitos fundos a ella applicados", uma vez que na obra até então haviam sido aplicados cento e dezasseis mil cento e trinta e oito cruzados. Já a 20 de dezembro de 1615, o Santíssimo Sacramento tinha sido colocado no novo templo (Lopes, 1965-66, p. 145). Esta referência sugere que por essa data já se realizava a celebração de serviços litúrgicos no altar ou outro espaço que servisse de tal no edifício que iria servir de nova Catedral o que, implicitamente, também incluiria a prática musical, pelo menos, do cantochão. A partir de 1618 continuou a Catedral recebendo os três mil cruzados do pastel até à Restauração, tendo sido gastos mais sessenta e seis mil cruzados nas obras até 1640 (Maldonado, 1990, p. 441). Após a Restauração, os três mil cruzados foram desviados para financiar a fortificação da costa da ilha, argumentando D. João IV que esta quantia era dada havia mais de sessenta anos e que nesse espaço tinha sido o dinheiro gasto em despesas supérfluas. No entanto, a 11 de março de 1644, o mesmo monarca revogava essa decisão, determinando que, tendo em consideração a Catedral tinha de se acabar e aperfeiçoar, fossem novamente dados os três mil cruzados anuais para a conclusão das obras (Laranjeira, 2008, p. 18).

Relativamente às obras no interior do novo templo, a capela-mor foi mandada dourar no tempo de D. João IV, assim como aprimorar a sacristia, com um custo de mais de sessenta e seis contos. O seu sucessor, D. Afonso VI acompanhou as obras e ofereceu vários paramentos para a Catedral, sendo estes benefícios continuados por D. Pedro II. Só a 16 de março de 1683 foi extinto o cargo de mestre de obras da Catedral (Laranjeira, 2008, p. 18). 
É importante referir a utilização continuada da primitiva igreja de São Salvador ao mesmo tempo que era envolvida pela obra da nova Catedral, o que não implicou o desmantelamento imediato da igreja paroquial. Uma das referências que corroboram esta afirmação foi a já mencionada cerimónia de lançamento da primeira pedra. Aí é referido que a procissão saiu da igreja de São Salvador, o que sugere que a dita igreja estaria ainda em plena atividade (Laranjeira, 2008, p. 15). Neste caso a existência do templo seria imprescindível ao desempenho regular das respetivas atividades litúrgico-musicais. Não será de todo irrelevante mencionar os transtornos causados por essa fase transitória entre os dois templos, que se arrastou por quase um século. A título de exemplo veja-se o caso da construção da capela-mor da Catedral de Évora nas primeiras décadas do século XVIII. Durante o período em durou a construção, muito próximo daquele da Catedral angrense, o coro-baixo da Catedral eborense foi transferido provisoriamente para o meio da nave central, o que terá alterado a dinâmica da atividade litúrgico-musical desse templo (Henriques, 2018, p. 88). Deste modo, embora com poucos detalhes sobre como se processou essa transição em Angra, é de supor que, com maior ou menor incidência, também a atividade litúrgicomusical do coro da Catedral de Angra também terá sido afetada.

Desconhece-se quaisquer detalhes arquitetónicos do interior da igreja paroquial de São Salvador. No que diz respeito à nova Catedral, o padre António Cordeiro traça uma descrição geral da mesma cerca de um século após a o termo das obras de pedraria e alvenaria. De acordo com este jesuíta, a Catedral estava dividida em três naves, com o "coro capitular em cima da entrada" (Cordeiro, 1717, p. 279). Possuía quatro capelas de cada parte, duas menos fundas e duas tão grandes "que podiao ser Capellas mores, entre as quaes na nave do meyo está o capitular coro de bayxo, \& logo se segue a Capella mor" (Cordeiro, 1717, p. 280). Cordeiro descreve a localização dos dois coros capitulares, onde diariamente os cónegos, beneficiados e capelães tinham a obrigação de celebrar os vários ofícios, que corresponde à respetiva localização dos mesmos ainda no início do século XX.

No coro-baixo da Catedral encontrava-se o cadeiral dos capitulares, como descrito pelo padre Jerónimo Emiliano de Andrade em 1843. Como se vê na iconografia existente do início do século XX, estaria a estante de coro ao centro do coro, ladeada pelo cadeiral. Tinha doze lugares a cada lado, para as dignidades e cónegos, sendo a primeira cadeira da capítula (rematada com as armas reais), e em baixo, os bancos destinados aos beneficiados e párocos, para os capelães e moços do coro (Costa, 1867, p. 94). Este tipo de descrição, embora sendo oitocentista, reflete em parte aquilo que seria a realidade da Catedral após a conclusão das obras do seu interior. Ainda em 1708 era arrematada a feitura do cadeiral para o coro-alto, que deixou de ser utilizado como tal em altura posterior (Costa, 1867, p. 93).

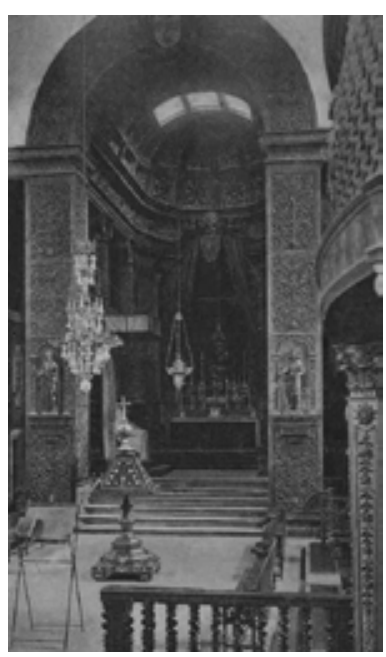

Coro baixo capitular da Catedral de Angra no início do século XX. Postal do início do século XX, de autor desconhecido. 
No respeitante aos cargos musicais da Catedral, que se desenvolveram simultaneamente com as obras da nova Catedral, conhece-se nas últimas décadas do século XVI a presença do padre Francisco Vaz como mestre de capela, acumulando também as funções de organista. Desconhece-se quanto tempo permaneceu nesses cargos, embora o seu falecimento tenha ocorrida em 1622 (Valença, 1990, p. 141-142). Em 1595 foi realizado contrato para a compra de novos órgãos ${ }^{1}$ para a Catedral ao clérigo de missa Nicolau de Resende, a fim de substituir os "de realejo" aí existentes (Lopes, 1965-66, p. 144). Certamente com intenção de guarnecer o novo tempo que ora se construía, a substituição dos órgãos de realejo existentes por outros, mais atualizados aos padrões da época, seria um melhoramento considerável na atividade musical da Catedral. Em termos de organistas da Catedral, desconhecem-se nomes entre Francisco Vaz e o padre João Baptista Camelo, que surge como tangedor dos órgãos no ano de 1688 (Mota, 2007, p. 36).

No que concerne aos mestres de capela que desempenharam atividade ao longo da primeira metade do século XVII, as referências, embora vagas, identificam a presença de três indivíduos a ocupar esse cargo. Deste modo, conhece-se a presença do já referido Francisco Vaz, de Gonçalo Nunes, nomeado mestre de capela no ano de 1622 por morte do antecessor Francisco Vaz, ${ }^{2}$ e Francisco de Almeida, sub-chantre da Catedral, nomeado para o mesmo cargo em 1640, por morte do antecessor, Gonçalo Nunes. ${ }^{3}$ Estes parecem ter sido as três figuras centrais nos destinos musicais da Catedral de Angra. Porém, para além destas notas biográficas, não se conhecem mais detalhes acerca da sua atividade. Também são escassos os detalhes respeitantes ao património musical (composições musicais) polifónico que seria realizado na Catedral ao longo do século XVII à exceção dos exemplos que serão referidos posteriormente.

No fundo musical do Arquivo Capitular da Sé de Angra foram encontrados em 2012 três livros de coro impressos de polifonia vocal sacra, contendo obras de dois destacados compositores portugueses da primeira metade do século XVII: Duarte Lobo e Fr. Manuel Cardoso (Henriques, 2012, p. 64). Trata-se do Cantica Beatae Mariae Virginis, vulgo Magnificat de Duarte Lobo, obra impressa em por João Moreto na Oficina Plantiniana de Antuérpia no ano de 1605. Compreende dezasseis versões polifónicas do cântico Magnificat distribuídas pelos oito tons, uma correspondendo aos versos ímpares e outra para os versos pares (Borges, 1986, p. 120-121). O mesmo ocorre com o segundo volume, também com dezasseis

1 Aqui, o termo "órgãos" é utilizado no plural, embora se desconheça se se tratava apenas de um ou dois instrumentos. O termo é por vezes utilizado no plural para designar apenas um instrumentos.

Arquivo Nacional da Torre do Tombo, Chancelaria Antiga da Ordem de Cristo, Livro 34, f. 262v. 
versões polifónicas do Magnificat, nos oito tons com uma versão para os versos ímpares e outra para os versos pares. O volume foi impresso em Lisboa na oficina de Pedro Craesbeeck no ano de 1613. Em 1621 foi impresso por Baltazar Moreto na Oficina Plantiniana de Antuérpia o terceiro volume de polifonia hoje existente no Arquivo Capitular da Catedral, o primeiro Liber Missarum de Duarte Lobo. O livro compreende as antífonas para a aspersão Asperges me e Vidi aquam, oito missas entre quatro e oito vozes, entre as quais cinco missas-paródia, três delas sobre motetes de Francisco Guerrero e duas sobre motetes Giovanni Pierluigi da Palestrina. O volume encerra com dois motetes fúnebres, Pater peccavi para cinco vozes e Audivi vocem de caelo para seis vozes (Henriques, 2013, p. 34).

Desconhece-se a data em que estes três volumes vieram parar à Catedral de Angra, nem quais os indivíduos envolvidos na sua aquisição, uma vez que nenhum dos livros possui quaisquer marcas de posse ou anotações que o sugiram. Os arquivos da Catedral também não forneceram ainda qualquer informação sobre os ditos volumes (Henriques, 2012, p. 64-65). Em todo o caso, com base nas datas de impressão, assim como alguns casos de aquisição dos mesmos por parte de catedrais do continente português, poder-se-á avançar algumas hipóteses em termos de datas. Ao mesmo tempo, o que se conhece em termos da circulação de música no espaço Ibérico durante o século XVII poderá também contribuir para um possível cenário sobre a sua vinda para a Angra.

O ano de 1605, data da impressão do livro de Magnificat de Lobo, e 1621, data da impressão do Liber Missarum do mesmo compositor, situam-se como balizas temporais do objeto em análise no presente estudo. Para estes dois exemplos, encontra-se também alguma correspondência entre Lobo e a Oficina Plantiniana relativa ao desenvolvimento do respetivo processo de impressão dos desses dois volumes.

De acordo com uma carta, datada de 24 de julho de 1600, sabe-se que do livro de 1605 imprimiram-se trezentos exemplares, que custaram quatrocentos e vinte ducados (Borges, 1986, p. 121). No Grand livre Au Soleil 1600-1608 da Oficina Plantiniana encontra-se uma entrada referente a 18 de janeiro de 1605. Nesse dia, foram os trezentos exemplares metidos em três arcas (cem em cada), sendo as mesmas entregues a António Fallero que sairia de Calais cabendo-lhe a entrega a Lobo (Borges, 1986, p. 126). Partindo desta referência, percebe-se que as arcas terão saído de Calais no início de 1605 e, certamente, terão chegado a Lisboa no mesmo ano. A partir desta cidade terá sido, então, feita a distribuição dos ditos exemplares pelas outras instituições, incluindo aquelas onde se encontram atualmente. A título de exemplo, sabe-se que no inventário da sacristia da Catedral nova de Coimbra, datado de 1635, surge já tanto o livro de Magnificat, como o primeiro livro de missas de Lobo, o último deles impresso dez anos antes. De Fr. Manuel Cardoso surge apenas um livro de missas, certamente o livro que

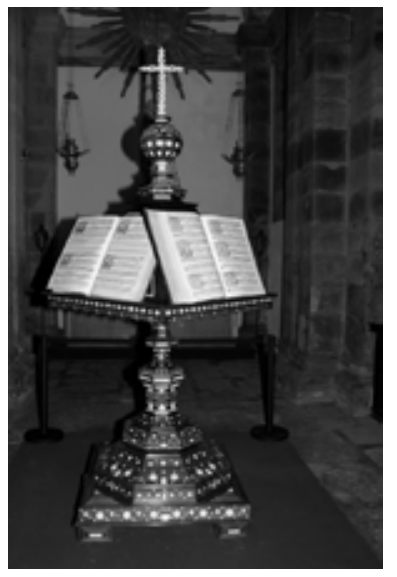

Liber Missarum e Cantica Beatae Mariae Virginis de Duarte Lobo na estante de coro proveniente do antigo Convento de São Francisco de Angra. Foto Mike Maciel. 
imprimiu em 1625, não existindo menção ao livro de Magnificat (Alegria, 1985, p. 52). ${ }^{4}$ Esta referência leva a analisar o tempo que demorava cada instituição a receber os respetivos livros de polifonia. Por um lado, sabe-se, como se viu anteriormente, que Lobo terá recebido o livro de Magnificat no ano em que foi impresso, 1605, e que a Catedral de Coimbra tinha-o no seu inventário em 1635, assim como o livro de missas impresso em 1621. Já mais tardio é o inventário realizado na Catedral de Elvas no ano de $1678 .^{5}$ Neste documento encontram-se listados os dois livros de Duarte Lobo, assim como o de Fr. Manuel Cardoso, junto com outros volumes de Filipe de Magalhães, Cristóbal de Morales, Tomás Luis de Victoria e Philippe Rogier. Curiosamente, a Diocese de Elvas foi criada apenas trinta e seis anos após a de Angra, ainda em pleno século XVI, o que a coloca muito próxima da diocese açoriana em termos da sua organização litúrgicomusical. De facto, a presença dos livros de coro no inventário de 1678 pressupõe que já estivessem em uso na Catedral no período anterior à sua realização. Isto leva a crer que, num espaço de meio século, as obras de Lobo e Cardoso estariam já difundidas pelas catedrais e igrejas portuguesas, tendo também chegado a Angra durante esse espaço de tempo, talvez mais prolongado que Coimbra, por via da viagem marítima que consumiria bastante mais tempo. Por estas contas, supõe-se que os livros tivessem chegado a Angra muito possivelmente na década de 1630 ou no período imediato à Restauração.

Uma outra referência reveste-se de alguma importância porque identifica uma aquisição do livro de missas de 1621. Trata-se de uma nota capitular da sessão do Cabido da Catedral de Coimbra realizada a 4 de dezembro de 1623. Esta nota, registada pelo secretário do Cabido João de Vilas Boas, foi aberta na sessão capitular uma carta de Duarte Lobo, beneficiado na Catedral de Lisboa, tendose entregado também um livro de canto de órgão que este havia enviado junto. Assentou-se que se mandasse averiguar o valor do livro a fim de "se lhe mandar pagar o q' parecesse" (Alegria, 1984, p. 42). José Augusto Alegria aponta esta nota capitular como um exemplo da forma como os compositores da época distribuíam as obras sem indicarem o custo, "sujeitando-se à maior ou menor generosidade das Corporações que as recebiam" (Alegria, 1984, p. 44). Desconhece-se se caso semelhante terá ocorrido na Catedral de Angra, não se estabelecendo qualquer tipo de comparação entre os fundos disponíveis na Catedral conimbricense para a aquisição de repertório musical com os fundos da Catedral angrense, com maiores constrangimentos, como se vê pelos sucessivos aumentos das dignidades e cónegos ao longo do século XVI, visto as quantias que recebiam serem

4 Existia no inventário o livro de Magnificat de Filipe Magalhães e um livro de Vésperas de Juan Esquivel que, junto com o livro de Magnificat de Lobo, perfaziam três obras onde estavam presentes versões polifónicas deste cântico o que, leva a crer, não justificava a aquisição do livro de Cardoso.

5

Alguns excertos deste inventário foram referidos pelo musicólogo Manuel Joaquim na série de artigos intitulados

"Documentos para a História da Música na Sé de Elvas" (n. 11), publicados no Jornal de Elvas, n. 65. 
manifestamente insuficientes ao seu mantimento e desempenho das respetivas atividades (Mota, 2007, p. 18).

Ressalta um outro detalhe de alguma importância no que respeita ao exemplo conimbricense acima referido. Trata-se de quem adquiriu estes livros de coro polifónicos. A referência documental aponta para o cenário de decisão sobre o pagamento do livro de missas de Lobo pertencente ao Cabido da Catedral, que o decidiria em sessão capitular. Isto significa que era o Cabido da Catedral, pelo menos nesse caso de Coimbra, quem tomava a última decisão sobre o repertório a adquirir para o serviço musical da Catedral e, por conseguinte, era também esta corporação que custeava a respetiva aquisição. Certamente haveria participação de outras figuras, nomeadamente do plano musical da instituição, que teriam uma palavra avaliadora sobre o repertório a adquirir. Estas figuras seriam possivelmente o chantre, ou sub-chantre, o mestre de capela e ainda o organista ou outro cantor ou mestre de música com mais antiguidade na instituição. Este poderá ter sido o caso no que diz respeito aos livros da Catedral de Angra.

Em todo o caso, o período que circunda a impressão destes três livros de coro correspondeu a um período de pouca estabilidade no governo da Diocese de Angra. A centúria de seiscentos abriu com a nomeação de D. Jerónimo Teixeira Cabral para Bispo de Angra, onde permaneceu até 1612, ano em que passou à Diocese de Miranda. Durante o seu bispado foi construído o claustro da Catedral (Mota, 2007, p. 125-126). Foi também um bispo bastante ativo em termos de proibições de comportamentos, nomeadamente dos foliões bailarem nas capelas-mores das igrejas em dias de coroações do Espírito Santo. Sucedeu-lhe D. Agostinho Ribeiro, confirmado por alvará de 14 de julho de 1614, permaneceu como governador do Bispado até ao seu falecimento a 12 de julho de 1621. Foi conhecido pelo estilo eloquente da sua oratória e elevado poder em mover as massas de fiéis nos templos onde pregava (Mota, 2007, p.126-127). Seguiram-se alguns bispados curta duração, nomeadamente o de D. Pedro da Costa Leal, que tomou posse da diocese a 24 de agosto de 1623, cuja relação com a governança da cidade não foi propriamente muito pacífica. D. João Pimental de Abreu, que permaneceu na diocese de 1626 a 1632, também não granjeou grande popularidade na cidade, sendo criticado pelo seu demasiado apego aos bens materiais. Pelo contrário, D. Fr. António da Ressurreição, Bispo de Angra entre 1635 e 1637, ficou conhecido pelo seu desapego aos bens materiais, sendo-lhe colados adjetivos como modesto, sem vaidades humanas e de "reformados costumes" (Mota, 2007, p. 127-129). A partir deste bispo ocorreu um longo período de trinta e quatro anos de sede vacante até à confirmação de D. Fr. Lourenço de Castro a 18 de maio de 1671. Este longo hiato em termos da governação do bispado terá sido certamente influenciado pelos acontecimentos em torno da Restauração, nomeadamente a guerra com Espanha que apenas teve desfecho em 1668. Após a Restauração, refere o padre Manuel Luís Maldonado, esteve o bispado vago por se haver aclamado D. João IV "e não quererem os Summos pontífices aceitar a nomeação dos Bispos que o dito Senhor Rey lhes aprezentaua" (Maldonado, 1990, p. 135). 
Durante os anos de sede vacante governou o bispado como vigário geral e provisor o licenciado Gaspar Cardoso Cardim. Este chegou a Angra, já rendida a fortaleza de São Filipe, a 23 de março de 1642 na comitiva militar do general António de Saldanha (Maldonado, 1990, p. 243). Deste modo, torna-se difícil perceber a sucessão nos cargos de governação do Bispado de Angra até à década de 1670, uma vez que, não só as crónicas não são pouco claras em termos dos indivíduos que se foram sucedendo, como também o próprio percurso governativo dos mesmos não permite vislumbrar quaisquer tipos de investimentos onde se pudesse incluir a aquisição dos livros de polifonia.

Folheando os três volumes, sobretudo o livro de missas, consegue-se extrair algumas leituras a partir do seu manuseamento. No caso do livro de Magnificat de Lobo, os fólios iniciais revelam sinais de terem sido muito manuseados, neste caso o canto inferior direito encontra-se amarelecido, faltando também o frontispício, dedicatória e licenças. Os sinais de maior uso concentram-se nas duas versões do cântico para o primeiro tom, faltando também os primeiros fólios da versão polifónica para os versos ímpares. O mesmo acontece com o livro de Magnificat de Cardoso, ao qual falta o frontispício e os primeiros fólios do índice e licenças. No entanto, contrariamente ao livro de Lobo, o de Cardoso não aparenta marcas de uso extensivo encontrando-se os fólios em bom estado de conservação. O Liber Missarum de 1621 é o volume onde se conseguem identificar mais extensivamente marcas da sua utilização. Tal como os outros dois volumes, também ao Liber Missarum falta o frontispício, sobrando apenas a dedicatória e licenças de impressão. Estas concentram-se sobretudo em três zonas principais do livro, em torno de três obras. A primeira destas obras é a antífona para a aspersão Asperges me, que seria cantada ao longo do ano litúrgico, exceto durante o período Pascal onde se deveria cantar a antífona Vidi aquam. As marcas de uso desta composição musical inicial são notórias, uma vez que seria a antífona cantada em todas as missas que exigissem a solenização com polifonia. As outras duas obras são a Missa De Beata Virgine, para quatro vozes, e a Missa pro Defunctis, para oito vozes. No caso da primeira obra, aquela com marcas mais profundas de um uso intensivo, há que referir o impulso que o culto da Virgem Maria teve a partir do Concílio de Trento, nomeadamente através da religiosidade popular (Enes, 1991, p. 261). O culto de Nossa Senhora do Rosário, apesar das suas raízes medievais, apresenta-se no período pós-tridentino como um culto novo, que terá uma forte expressão no arquipélago dos Açores, à qual a nova Catedral não será estranha incluindo uma capela dessa devoção da já existente confraria (Mota, 2007, p. 82-83). A missa em questão de Lobo estava destinada às festas comuns marianas ao longo do ano litúrgico podendo, deste modo, ser cantada nas festas marianas celebradas na Catedral.

O caso da Missa pro Defunctis justifica-se como uma das obras musicais destinadas a um momento específico da liturgia e que ser repetiria com grande frequência na atividade litúrgico-musical da Catedral. A versão para oito vozes de Lobo constituía um elemento de solenização de ofícios fúnebres mais importantes 
na cidade. Desde os aniversários, celebrados regularmente na Catedral no seguimento de instituições e legados de figuras importantes da nobreza e do clero local, também os ofícios celebrados após o falecimento de figuras de destaque na sociedade da urbe terceirense seriam solenizados com polifonia, intercalada com o usual ofício de cantochão. Um dos exemplos no respeitante à chegada de notícias a Angra da capital do reino foi aquela respeitante ao falecimento de el-rei D. João IV. Este monarca havia falecido a 6 de novembro de 1646 tendo a notícia chegado à cidade de Angra no início de março do ano seguinte. De acordo com o padre Manuel Luís Maldonado, fizeram-se as "demonstrações possiueis em ordem, aos lutos, e funerais das Exequias" (Maldonado, 1990, p. 358). Na Catedral montou-se uma eça no centro do coro capitular defronte da capelamor. As exéquias foram solenizadas "a todo o maior custo com tal pompa que não faltaram na asistencia" os ministros da Catedral, todos os párocos da cidade, assim como o clero extravagante e comunidades religiosas. Cantou-se "o officio a dous choros com toda a perfeição, porquanto para isso forão chamados todos os sogeitos mais cientes, e dextros na Muzica" (Maldonado, 1990, p. 360). Embora não havendo mais referências acerca de qual o ofício cantado, a presença da Missa pro Defunctis para oito vozes no Liber Missarum de Lobo, aliada à referência policoral na descrição de Maldonado, sugerem a possibilidade de ter sido interpretada a missa de Lobo, tendo a capela sido reforçada em termos de efetivos para essa cerimónia.

Em jeito de conclusão, pode-se adiantar que o desenvolvimento dos cargos musicais na Catedral de Angra, gradualmente estabelecidos após a criação da diocese em 1534, terão incentivado a aquisição de repertório polifónico para uso na Catedral. Os três livros, objeto do presente estudo, constituem até ao momento os exemplares mais antigos de repertório musical conhecido no arquipélago dos Açores. A sua associação à Catedral de Angra sugere que esta instituição estivesse em posição económica de adquirir os respetivos volumes, que à época não seriam baratos, sendo a mesma muito provavelmente realizada por intermédio do Cabido, à partida, a corporação com recursos e poder para realizar essa ação. Estes livros, escritos em polifonia imitativa ao jeito do que se fazia no século XVI, estavam destinados a um publico mais vasto e seriam utilizados pelos seis capelães-cantores e quatro moços de coro que provavelmente estariam sob a direção dos mestres de capela enumerados anteriormente. Deste modo os três livros presentes neste estudo revelam-se como importantes peças do património musical açoriano mas, ao mesmo tempo, importantes elementos no entendimento da atividade musical na Catedral de Angra ao longo do século XVII. 
Alegria, J. A. (1985). O Ensino e prática da Música nas Sés de Portugal (Da Reconquista aos fins do século XVI). Lisboa, Instituto de Cultura e Língua Portuguesa.

Alegria, J. A. (1984). Polifonistas Portugueses. Duarte Lobo. Filipe de Magalhães. Francisco Martins. Lisboa: Instituto de Cultura e Língua Portuguesa.

Andrade, J. E.de (1891). Topographia ou Descripção física, politica, civil, ecclesiastica, e histórica da Ilha Terceira dos Açôres. Parte Primeira anotada pelo vigário José Alves da Silva. Angra do Heroísmo: Livraria Religiosa - Editora.

Borges, A. (1986). Duarte Lobo (156?-1646): Studien zum Leben und Schaffen des portugiesischen Komponisten. Regensburg: Gustav Bosse Verlag.

Costa. F. (1867). Angra do Heroismo Ilha Terceira (Açores) (Os seus títulos, edifícios e estabelecimentos públicos). Angra do Heroísmo: Typ. do Governo Civil.

Costa, S. (2008). Açores: Nove Ilhas, Uma História. Berkeley, Institute of Governmental Studies Press/University of California.

Enes, M. F. (1991). Reforma Tridentina e Religião Vivida (Os Açores na Época Moderna). Ponta Delgada: Signo.

Henriques, L. (2018). "A nova capela-mor setecentista da Catedral de Évora: Uma abordagem ao seu impacto na atividade musical de Pedro Vaz Rego e Ignácio António Celestino". Arte y Patrimonio, n. 3, pp. 77-92. 
Henriques, L. (2013). "Polifonia na Sé de Angra: O Liber Missarum de Duarte Lobo". Cadernos de Musicologia - Glosas, n. 9, pp. 32-36.

Henriques, L. (2012). "Polifonia na Sé de Angra? Três Impressos de Sacra Portuguesa Seiscentista". Glosas, n. 6, pp. 64-65.

Laranjeira, M. (2008). São Salvador de Angra: uma catedral sebástica. Angra do Heroísmo: Instituto Açoriano de Cultura.

Leite, A. R. (2015). "A Sé de Angra, Cabeça do Bispado dos Açores". Norba, Revista de Arte, vol. XXXV, pp. 27-46.

Lopes, F. (1965-66). "Da Praça às Covas: Memórias de uma Velha Rua". Boletim do Instituto Histórico da Ilha Terceira, vol. 23-24, pp. 9-

Maldonado, M. L. (1990). Fenix Angrence. Volume II. Angra do Heroísmo: Instituto Histórico da Ilha Terceira.

Mota, V. (2007). Santa Sé do Salvador: Igreja Catedral dos Açores. Angra do Heroísmo: Sé de Angra.

Nery, R. V. e Castro, P. F. de (1992). História da Música (Sínteses de Cultura Portuguesa). Lisboa: Imprensa Nacional - Casa da Moeda.

Valença, M. (1990). A Arte Organística em Portugal (c. 1326 - 1750). Braga: [Editorial Franciscana]. 